\title{
Statistical Joint Modeling on Longitudinal Body Weight and CD4 Cell Progression with Survival Time-to-Death Predictors on HIV/AIDS Patients in Mekelle General Hospital, Ethiopia
}

Geberu Gebrerufael

Adigrat University

\section{Zeytu Asfaw}

Hawassa University

Dessie Chekole ( $\sim$ DESSIE.MELESE1@uog.edu.et)

University of Gondar

\section{Research}

Keywords: ART, CD4 Cell, HIV/AIDS, Longitudinal Data Analysis, Statistical Joint Modeling

Posted Date: December 9th, 2020

DOI: https://doi.org/10.21203/rs.3.rs-121687/v1

License: (9) (1) This work is licensed under a Creative Commons Attribution 4.0 International License.

Read Full License 
Statistical Joint Modeling on Longitudinal Body Weight and CD4 Cell Progression with Survival

Time-to-Death Predictors on HIVIAIDS Patients in Mekelle General Hospital, Ethiopia

${ }^{1}$ GebruGebremeskelGebrerufael, ${ }^{2}$ Zeytu Gashaw Asfaw, ${ }^{3 *}$ Dessie MeleseChekole

*corresponding author

1. Department of Statistics, College of Natural and Computational Science, Adigrat University, Adigrat, Ethiopia.

2. Department of Statistics, College of Natural and Computational Science, Hawassa University, Hawassa, Ethiopia.

3. Department of Statistics, College of Natural and Computational Science, University of Gondar, Gondar, Ethiopia.

${ }^{1}$ Email:gebrugebremeskel12@gmail.com,2Email:zeytugas@gmail.com, 3* Email:dessiecsa@ gmail.com. 


\begin{abstract}
This study assessed the impact of repeated biomarker measurements of statistical joint modeling on survival time-to-death and determines potential predictors of HIV/AIDS patients on ART in Mekelle General Hospital Ethiopia. A retrospective cohort study was conducted among HIV/AIDS patients who were under ART follow-up during September 11, 2013 - September 5, 2016, at Mekelle General Hospital, Ethiopia. The relationship between the two biomarkers CD4 cell and body weight with risk for survival time-to-death were statistically insignificant. Thus, death is less probable to occur in HIV/AIDS patients with a higher value of CD4 cell count and body weight progression. In the event process the sub-model, Baseline CD4, Fair, and Good Adherence, HIV/TB, and Sex were significant factors of risk to short survival Time-to-Death on HIV/AIDS patients. In the 1st longitudinal process sub-model, Baseline CD4, Ambulatory functional status, HIV/TB (yes), Time*Ambulatory functional status, Time*Working functional status, and Time*Baseline CD4 were the significant factors of $\sqrt{C D 4 \text { cell }}$ count progression. Moreover, In the 2nd longitudinal process sub-model, visit Time of follow-up, Age, Sex (male), Baseline weight, Time*Ambulatory and Time*Working functional status were the significant factors of $\log 10$ (bodyweight) progression. Both governmental and non-governmental stakeholders should pay special attention to HIV-positive adults, especially those who had developed HIV/TB, male, bedridden functional status, poor adherence, and lower Baseline CD4 cell count progression so that mortality due to HIV/AIDS optimally reduced.
\end{abstract}

Key-Words: ART; CD4 Cell; HIV/AIDS; Longitudinal Data Analysis; Statistical Joint Modeling. 


\section{Background}

It is about half of a century since the HIV epidemic has been a menace to this world. Following the reports of the first case in the early 1980s, the spread of HIV/AIDS has increased at an alarming rate. Despite global awareness, more than 70 million people were affected and 35 million people died due to HIV infection [1]. It is reported that, nearly 36.7 million people were living with HIV [1,2,3] and that more than 1 million people died globally in 2016 [2]. While adults ranging in age between 15 and 49 which constitutes about $0.8 \%$ worldwide were affected, the infection in Sub- Saharan Africa continues to be severe (4.2\%) and this accounts for about two-thirds of HIV people living in the world.

Although the infection varies considerably in different regions, the distribution of HIV/AIDS was more in Sub-Saharan Africa and represents about $60 \%$ of the victims of HIV/AIDS of the world. Among 800, 000 new HIV cases reported in Eastern and Sub-Saharan Africa, 12.9\% of the infected people were assessed for ART, and around 380, 000 people died of HIV/AIDS in 2017[4].

Ethiopia is one of the most highly affected among the seven countries that are greatest hit by the HIV/AIDS pandemic diseases in Sub-Saharan Africa [5]. Approximately about one million people living with HIV becomes the leading cause of mortality among 15-49 years of age that accounts for $43 \%$ of all population deaths in 2016, and approximately a total of 114,690 people died of AIDS-related conditions [6].

Anti-retroviral treatment (ART) was started in Ethiopia in 2003 formally with cost-sharing. However, the country initiated free ART in 2005 with the support of the Global Fund for Tuberculosis, AIDS, and Malaria (GFTAM), and the U.S. President Emergency Plan for AIDS Relief (PEPFAR). In the study area, Mekelle General Hospital has been begun ART delivery services follow up since September 2011 and up to now has been given a service, more than 10,000 HIV/AIDS patients [7]. But, the effectiveness of ART initiatives is not yet fully investigated especially how much support to prolong the survival of HIV patients in the study area and a nation to the larger domain. Thus, we have focused on examining the existing status and determining the potential predictors that could affect the survival of HIV patients, and suggesting realistic interventions to optimize patient's life quality. The CD4 cell count of a healthy individual must have at least 500 cells $/ \mathrm{mm} 3$ and below this level is an indication of an unhealthy condition, and when CD4 cell count reduces below 200/mm3, the person requires a 
diagnosis for AIDS [8,9]. CD4 counts decrease over time in persons who are not receiving ART, of course, the other way also true. Moreover, CD4 cell counts are affected by various demographic factors [10].

Authors have focused on patient's body weight and CD4 cell progression where both survival and longitudinal data are usually considered. Survival analysis involves the modeling of time to event data; in this context, death or failure is considered as" an event". In fact, separate modeling could be possible but usually, joint modeling is suggested for such studies and comparisons have been made with the separable models. Joint modeling is appropriate when one wants to predict the time to an event with covariates that are measured longitudinally and are related to the event. An underlying random effects structure links the survival and longitudinal sub-models and allows for individual-specific predictions.

Thus, the main purpose of the current study was to examine the current patient status in contrast with baseline facts and determine potential predictors through Joint modeling longitudinal analysis of body weight and CD4 cell as a biomarker of disease progression on shortening survival Time-to-Death predictors of HIV/AIDS patients on ART follow-up in Mekelle General Hospital.

\section{Methods}

\section{Study Area and period}

This study was conducted at Mekelle General Hospital, Tigray Region, and Northern Ethiopia on HIV/AIDS positive patients who initiated ART follow-up from September 11, 2013, until September 5, 2016.

\section{Study design and Data Source}

We have obtained data through a retrospective cohort study design where basically joint longitudinal and survival modeling has considered to determine potential predictors.

\section{Study Population}

All HIV/AIDS positive patients whose ages were 15 years and above treated on ART follow-up from the time September 11, 2013, to September 5, 2016, in Mekelle General Hospital. These are the study population if they fulfilled the inclusion criterion were considered in this study. 


\section{Sample size determination and sampling procedure}

In this, the researcher used a systematic random sampling procedure to select sample subjects from the list of the study population. Then, the researcher has used the survival sample size determination formula to achieve statistically significant results. Sample size calculation formula, the required sample size for this study was obtained as follows [11].

$$
\text { Death }=\frac{\left\{z_{\frac{\alpha}{2}}+\mathrm{Z}_{\beta}\right\}^{2}}{\Pi_{1} \Pi_{2}(\log H R)^{2}}
$$

The sample size was determined by taking the mortality rates in two groups of HIV positive on ART based on their WHO clinical stage as exposure status. Where, $Z_{\frac{0.05}{2}}=1.96, Z_{\beta}=0.84, \mathrm{HR}$ of exposures $=7.36, \Pi_{1}=$ Proportion of exposed group $(\mathrm{WHO}$ stage-IV $)=0.84, \Pi_{2}=$ Proportion of non-exposed group (WHO stage-II \& III) $=0.16$. Therefore, Death $=\frac{\{1.96+0.84\}^{2}}{0.84 * 0.16(\log 7.36)^{2}} \approx 77$ and also the probability of death was $35.5 \%$.

Then, $\mathrm{n}=$ Death $=\frac{\text { death }}{\operatorname{pr}(\text { death })}=\frac{77}{0.355} \approx 216$. The study participants were selected using systematic random sampling method of patients' unique identification number and were retrospectively from time September 11, 2013 to September 5, 2016. Then, the sample size for this current study is become 216 HIV positive subjects [12].

\section{Data Collection Procedure}

The relevant data were taken from HIV/AIDS patients under ART follow up charts and have been collected by two professional collectors and also one supervisor.

\section{Quality of data}

The quality of the data was controlled by data controllers from the ART section of the hospital. The controllers were taken intensive training by the Ministry of Health for different services. The data extraction tools and the variables included in the study were tested. Necessary amendments were made to the final data collection sheet.

\section{Study variables}

The response and predictor variables considered in this study were defined as follows. 


\section{Response Variables}

The longitudinal response variables were the progression of body weight (in $\mathrm{kg}$ ) and CD4 cell count (in cell/mm3) of HIV/AIDS Positive patients during the follow-up time from the date of ART initiation. The survival response variable was the survival time-to-death or censored (in the month) HIV/AIDS Positive patients during the follow-up time from the date of ART initiation. This was measured from the starting of treatment till the patient's time-to-death or censored of the last visit.

\section{Independent Variables}

The covariates (predictor) variables in the current study were considered potentially affect the body weight and CD4 cell count progression and then, aggravate the death of HIV/AIDS patients. Thus, study variables selected based on authors experience and empirical related literatures, for example [6, 13-15].

\section{Statistical Models of data analysis}

In this study, the authors used the survival model to investigate the determinant factors that can affect survival time after patients started taking treatment to death of the patient's and univariate longitudinal model analysis had been used to recognize determinant factors that affect the longitudinal change of CD4 cell count and body weight progression separately. And also, the statistical Joint longitudinal and survival analysis were used to assess the impact of the longitudinal change of body weight and CD4cell count progression on survival time-to-death of the HIV/AIDS patients.

Based on the complexity of the data and the desired objectives of the study, the authors have considered the following three types of different statistical data models:

A linear mixed-effects model (LMM) was used for continuous response variables for the longitudinal data like bodyweight \& CD4 cell count.

- Survival model for the continuous survival time-to-death response variable like the Cox proportional hazard model.

(- Statistical Joint model of longitudinal (bodyweight \& CD4 cell count) analysis for longitudinal measurements with survival time-to-death.

\section{Results}

Descriptive statistics of baseline covariates was illustrated (see supplementary file Table 1)

Descriptive statistics of baseline covariates was illustrated in Table 1. Thus, among 216 HIV/AIDS positive patients considered in the current study, 31 (14.4\%) of them were died while 
the remaining $185(85.6 \%)$ were censored and they may still alive, death with other case/competing interest and lost follow-up. The mean age, hemoglobin label and body weight of HIV/AIDS patients at the start of ART were 34.8 years, $13.6 \mathrm{gm} / 100 \mathrm{ml}$ and $49.2 \mathrm{k} . \mathrm{g}$ respectively. The average number of baseline CD4 cells count was 311.04 cells per mm3 with a standard deviation of 161cells per mm3 of blood implying that patients were at higher risk of getting HIV/AIDS related illness. Out of 216 HIV/AIDS patients 134 (62\%) were Female and $130(60 \%)$ were lived in urban area. Similarly, among the sampled HIV/AIDS patients 23(10.6\%) were with HIV/TB co-infected. Table-1 also revealed that the percentage of death in males (9.7\%) was higher than that of females (4.6\%) in HIV positive patients. Moreover, the percentage of death HIV/TB co-infected patient's (43.48) was higher than that of patients who did not have TB diseases (10.88\%). Finally, from, the percentage of death of HIV/AIDS positive patients who lived in rural (9.3\%) area was higher than those who lived in urban (5\%).

\section{Statistical joint model analysis}

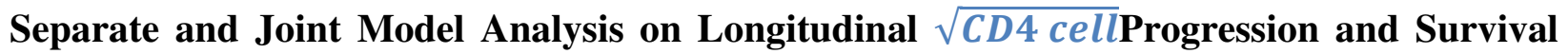
time-to-death (see supplementary file Table 2)

In this section, we determined the variables to be included in the statistical joint model authors have considered an automatic backward variable selection method (step AIC in R). The survival sub-model was consistent with the results from the separate survival analysis. The differences in magnitudes of the parameter estimates were minor, and there was some parameter difference in terms of statistical significance. The results from the separate and joint analysis were slightly similar to each other. In the survival sub-model fair adherence, good adherence, Baseline CD4, HIV/TB, Baseline weight, and sex were statistically significant predictors of the risk of death. However, the category of functional status and education level was not statistically significant.

longitudinal analysis sub-model of the joint model time, Baseline CD4, Baseline weight, HIV/TB(Yes), married, divorced, ambulatory functional status, age, time*Baseline CD4, time*ambulatory, time*working and time*HIV/TB (yes) all predictors included in the model were statistically significantly associated with the progression of

$\sqrt{C D 4 \text { cell }}$ Count. Therefore, from this result Baseline, CD4 \&Baseline weight is positively associated with the trajectory of the $\sqrt{C D 4 \text { cell }}$ count. And also, significantly lower risk for shortening the survival time to death associated with HIV/AIDS patients having higher Baseline CD4 \&Baseline weight. While the estimated parameters of the two models were slightly similar to each other and not identical, the estimate of the association parameters in the Joint Model was significantly different from zero. This 
association indicates that higher $\sqrt{C D 4 \text { cell }}$ progression was associated with a lower risk of survival time and time to death.

The residual variability was smaller in the joint analysis (5.9731) compared to the relative linear mixed Effects analysis (6.0025) which was probably because the standard errors were adjusted for the Correlation between the longitudinal and survival responses. Finally, when we assessed the overall performance of both the separate and joint statistical models in terms of a model less complex and goodness of fit, the joint statistical model was performed better.

As a result, the joint model was better as it has a smaller total AIC than the separate model. Also, the statistical significance of both the association parameters was also evidence that the statistical joint model analysis was better than the Separate models [24].

Separate and Joint Model Analysis on $\log _{10}$ (Body-Weight) progression and Survival Time-toDeath

In this subsection, the survival sub-model was consistent with the results from the separate model of survival analysis, Table 3. The differences in magnitudes of the parameter estimates were minor and there was some parameter difference in terms of statistical significance. The results from the separate and joint model analysis were slightly similar to each other. This survival sub-model is given below. Fair Adherence, good Adherence, Baseline CD4, Baseline weight, ambulatory Function status, working Function status, primary education level, secondary education level, tertiary education level, and Sex (male) were statistically significant predictors with the risk of shortening survival time-To-death.

Table 3: Shows Comparison of Separate and joint model analysis of $\log _{10}$ (Body-Weight) progression with survival Time-to-death.

\begin{tabular}{|c|c|c|c|c|c|c|c|c|}
\hline Parameter & \multicolumn{4}{|c|}{ Separate model analysis of survival } & \multicolumn{4}{|c|}{ Joint model sub model } \\
\hline Fixed effect & $\hat{\mathrm{B}}$ & $\operatorname{Se}(\hat{B})$ & z-value & $\operatorname{Pr}(>|z|)$ & $\hat{\mathrm{B}}$ & $\mathrm{Se}(\hat{\mathrm{B}})$ & z-value & p-value \\
\hline Function status & & & & & & & & \\
\hline Bedridden(R) & ---------- & ----------- & --------- & ------------ & -------- & -------- & ----------- & ------------ \\
\hline Ambulatory & 0.732 & 0.595 & 1.231 & 0.218 & 1.060 & 0.0001 & $1.6 * 10^{4}$ & $<0.0001 *$ \\
\hline Working & 0.4316 & 0.7092 & 0.609 & 0.543 & 0.6241 & 0.0001 & $4.79 * 10^{3}$ & $<0.0001 *$ \\
\hline Baseline CD4 & 0.00513 & 0.001433 & 3.578 & $0.00037 *$ & 0.0035 & 0.0014 & 2.46 & $0.0137 *$ \\
\hline adherence & & & & & & & & \\
\hline
\end{tabular}




\begin{tabular}{|c|c|c|c|c|c|c|c|c|}
\hline $\begin{array}{l}\text { Poor(R) } \\
\text { Fair } \\
\text { Good }\end{array}$ & $\begin{array}{l}-1.493 \\
-1.837\end{array}$ & $\begin{array}{l}0.513 \\
0.64098\end{array}$ & $\begin{array}{l}------ \\
-2.914 \\
-2.866\end{array}$ & $\begin{array}{l}-------- \\
0.00357 * \\
0.004163 *\end{array}$ & $\begin{array}{l}------ \\
1.6216 \\
-1.55\end{array}$ & $\begin{array}{l}-------- \\
0.0000 \\
0.0000\end{array}$ & $\begin{array}{l}-2.17 * 10^{5} \\
-3.11 * 10^{4}\end{array}$ & $\begin{array}{l}<0.0001 * \\
<0.0001 *\end{array}$ \\
\hline Baseline weight & -0.0402 & 0.0229 & -1.755 & $0.04791^{*}$ & -0.084 & 0.0119 & -7.0768 & $0<0.0001 *$ \\
\hline Sex & & & & & & \multirow[b]{2}{*}{--------- } & \multirow[b]{2}{*}{$4.9 * 10^{3}$} & \multirow[b]{2}{*}{ <0.0001* } \\
\hline $\begin{array}{l}\text { female }(\mathrm{R}) \\
\text { male }\end{array}$ & $\begin{array}{l}-------- \\
1.443\end{array}$ & $\begin{array}{l}--------- \\
0.494\end{array}$ & ------- & $\begin{array}{l}-------- \\
0.00349 *\end{array}$ & -------- & & & \\
\hline \multicolumn{9}{|l|}{ Education } \\
\hline $\begin{array}{l}\text { Illiterate(R) } \\
\text { primary } \\
\text { secondary } \\
\text { Tertiary }\end{array}$ & $\begin{array}{l}--------- \\
0.5475 \\
-0.5086 \\
-1.287\end{array}$ & $\begin{array}{l}0.4964 \\
0.547 \\
1.096\end{array}$ & $\begin{array}{l}------- \\
1.103 \\
-0.929 \\
-1.175\end{array}$ & $\begin{array}{l}0.2699 \\
0.3527 \\
0.2400\end{array}$ & $\begin{array}{l}------- \\
0.6073 \\
-0.479 \\
-1.13\end{array}$ & $\begin{array}{l}0.0001 \\
0.0001 \\
0.0000\end{array}$ & $\begin{array}{l}-------- \\
5.29 * 10^{3} \\
-8.88 * 10^{3} \\
-5.28 * 10^{4}\end{array}$ & $\begin{array}{l}<0.0001 * \\
<0.0001 * \\
<0.0001 *\end{array}$ \\
\hline Parameter & \multicolumn{4}{|c|}{ Separate model analysis of longitudinal } & \multicolumn{4}{|c|}{ Joint model-sub model } \\
\hline Fixed effect & $\hat{\mathrm{B}}$ & $\operatorname{Se}(\hat{B})$ & z-value & $\operatorname{Pr}(>|z|)$ & $\hat{\mathrm{B}}$ & $\operatorname{Se}(\hat{B})$ & z-value & $\begin{array}{l}\operatorname{Pr}( \\
>|z|)\end{array}$ \\
\hline Intercept & 1.573 & 0.024 & 65.48 & $0.0000^{*}$ & 1.574 & 0.0081 & 194.98 & $<0.0001 *$ \\
\hline Time & 0.00334 & 0.00279 & 1.197 & 0.2314 & 0.0033 & 0.0026 & 1.2658 & 0.2056 \\
\hline Age & 0.0011 & 0.00038 & 2.944 & $0.0036^{*}$ & 0.0011 & 0.0004 & 3.001 & $0.0027 *$ \\
\hline Sex & & & & & & \multirow[b]{2}{*}{0.0086} & \multirow[b]{2}{*}{4.6119} & \multirow[b]{2}{*}{$\begin{array}{l}---------- \\
<0.0001 *\end{array}$} \\
\hline $\begin{array}{l}\text { female(R) } \\
\text { male }\end{array}$ & $\begin{array}{l}---------- \\
0.0396\end{array}$ & $\begin{array}{l}---------- \\
0.0090\end{array}$ & 4.39 & $\begin{array}{l}------------ \\
- \\
0.0000 *\end{array}$ & ------- & & & \\
\hline \multicolumn{9}{|l|}{ Marital } \\
\hline $\begin{array}{l}\text { single }(\mathrm{R}) \\
\text { married } \\
\text { Divorced } \\
\text { Widowed }\end{array}$ & $\begin{array}{l}\text {---------- } \\
0.01377 \\
0.0155 \\
0.00449\end{array}$ & $\begin{array}{l}-------- \\
0.0104 \\
0.0137 \\
0.019\end{array}$ & $\begin{array}{l}1.323 \\
1.13 \\
0.236\end{array}$ & $\begin{array}{l}--187 \\
0.2599 \\
0.8135\end{array}$ & $\begin{array}{l}------- \\
0.0138 \\
0.0153 \\
0.0036\end{array}$ & $\begin{array}{l}------ \\
0.0078 \\
0.0102 \\
0.0086\end{array}$ & $\begin{array}{l}------- \\
1.7782 \\
1.5075 \\
0.4217\end{array}$ & $\begin{array}{l}-0.0754 \\
0.1317 \\
0.6732\end{array}$ \\
\hline Baseline CD4 & 0.00012 & 0.00004 & 3.012 & $0.0029 *$ & 0.0001 & 0.0000 & 3.3336 & $0.0009^{*}$ \\
\hline Baseline weight. & 0.0066 & 0.00061 & 10.83 & $0.0000^{*}$ & 0.0068 & 0.0006 & 11.80 & $<0.0001 *$ \\
\hline \multicolumn{9}{|l|}{ Function status } \\
\hline $\begin{array}{l}\text { Bedridden(R) } \\
\text { Ambulatory } \\
\text { Working }\end{array}$ & $\begin{array}{l}--------- \\
0.036 \\
0.0718\end{array}$ & $\begin{array}{l}--------- \\
0.0182 \\
0.0173\end{array}$ & $\begin{array}{l}--------- \\
1.97 \\
4.146\end{array}$ & $\begin{array}{l}--------- \\
0.0498 * \\
0.0000 *\end{array}$ & $\begin{array}{l}0.0357 \\
0.0714\end{array}$ & 0.0075 & $\begin{array}{l}------- \\
4.731 \\
10.43\end{array}$ & $\begin{array}{l}<0.0001 * \\
<0.0001 *\end{array}$ \\
\hline $\begin{array}{l}\text { time: } \\
\text { BaselineCD4 }\end{array}$ & 0.00002 & 0.000008 & 1.907 & $0.0467 *$ & 0.0001 & 0.0000 & 2.0466 & $0.0407^{*}$ \\
\hline
\end{tabular}




\begin{tabular}{|l|l|l|l|l|l|l|l|l|}
\hline Random effect & variance & StdDev & & & Variance & StdDev & \\
\hline (Intercept) & 0.007 & 0.0838 & & & 0.007 & 0.0838 & & \\
\hline Time & 0.00025 & 0.0157 & & & 0.00025 & 0.0157 & & \\
\hline Residual & 0.0015 & 0.0392 & & & 0.0015 & 0.0392 & & \\
\hline Association & ---------- & ---------- & --------- & ------------ & -1.975 & 1.0065 & -1.9627 & 0.02798 \\
\hline AIC & 3283.261 & & 3327.523 & & \\
\hline
\end{tabular}

Table 3, longitudinal analysis sub-model of the joint model age, Baseline CD4, Baseline weight, Ambulatory Function status, working Function status, time: Baseline CD4, and sex (male) all predictors included in the model were significant predictors of progression on the $\log$ (bodyweight). Finally, the estimated parameters of the two models (separate and joint models) were slightly similar to each other but not identical. However, the estimates of the association parameters in the statistical Joint model analysis were significantly different from zero. This provides that there was enough evidence of an association between the two sub-models. The estimate of association (Gamma_2= -1.975) indicating that the higher Log10 (Body-Weight) progression is associated with the lower risk of shortening survival Time-To-death. When evaluating the overall performance of both the separate and joint models in terms of a model less complex and goodness of fit, the joint model was performed better. As a result, the joint model was better as it has a smaller total AIC than the separate model. The statistical significance of both the association parameters was also strong evidence that the joint model analysis was better than the Separate models [24].

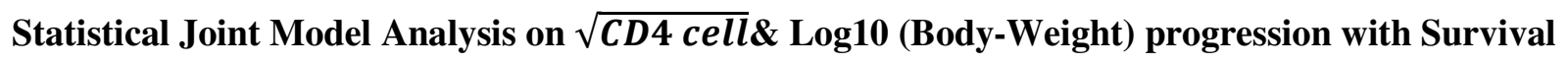 Time-to-Death}

Table 4 shows that the 1 st longitudinal process sub-model was for $\sqrt{C D 4 \text { cell }}$ count and the second was for log (bodyweight). Based on this Table, Baseline CD4, Ambulatory functional status, HIV/TB (yes), Time*Ambulatory, Time*Working, and Time*Baseline CD4 were significant factors of $\sqrt{C D 4 \text { cell }}$ count progression. The visit time of follow-up, age, sex(male), Baseline weight, Ambulatory \& working functional status were significant factors of $\log$ (bodyweight) progression and Baseline CD4, fair adherence, good adherence, HIV/TB and sex were significant factors of risk to short survival Time-to-Death of HIV/AIDS patients. The associations of the $\sqrt{C D 4 \text { cell }}$ count on survival Time-To-Death and log (Bodyweight) on survival Time-To-Death of HIV/AIDS patients were statistically significant when those two 
biomarkers of longitudinal repeated measurements with survival time-to-death were fitted simultaneously. The association parameters were negative for both statistical joint sub-models.

Table 4: Result of joint model of longitudinal $\sqrt{\text { CD4 cell }} \& \log$ (body weight) progression with survival Time-To-Death of HIV/AIDS patients.

\begin{tabular}{|c|c|c|c|c|c|c|c|c|c|c|}
\hline \multicolumn{5}{|c|}{$\begin{array}{l}\text { Event process sub survival model of } \sqrt{C D 4 \text { cell }} \text { on Time-To- } \\
\text { Death }\end{array}$} & \multicolumn{6}{|c|}{$\begin{array}{c}\text { Event process sub survival model of } \sqrt{C D 4 \text { cell } \&} \\
\log \text { (weight) with Time-To-Death }\end{array}$} \\
\hline Parameters & $\hat{\mathrm{B}}$ & $\mathrm{Se}(\hat{\mathrm{B}})$ & z-value & $\operatorname{Pr}(>|z|)$ & $\hat{\mathrm{B}}$ & $\operatorname{Se}(\hat{B})$ & & & & $(>|z|)$ \\
\hline Functional status & \multirow[b]{2}{*}{------- } & \multirow[b]{2}{*}{------- } & \multirow[b]{2}{*}{------ } & \multirow[b]{2}{*}{------- } & \multirow[b]{2}{*}{-------- } & \multirow[b]{2}{*}{------- } & \multirow{2}{*}{\multicolumn{2}{|c|}{------ }} & \multirow{2}{*}{\multicolumn{2}{|c|}{------- }} \\
\hline Bedridden $(\mathrm{R})$ & & & & & & & & & & \\
\hline Ambulatory & -0.5247 & 1.0577 & -0.496 & 0.125 & -0.439 & 1.00 & \multicolumn{2}{|c|}{-0.439} & \multicolumn{2}{|c|}{0.1703} \\
\hline Working & -0.4200 & 1.0332 & -0.4065 & 0.178 & -0.3183 & 1.012 & & & \multicolumn{2}{|c|}{0.1914} \\
\hline \multicolumn{11}{|l|}{ Sex } \\
\hline female(R) & \multirow{2}{*}{1.3408} & \multirow{2}{*}{0.6136} & \multirow{2}{*}{ 2.1851 } & \multirow{2}{*}{$0.0289 *$} & --------- & \multirow{2}{*}{0.5383} & \multicolumn{2}{|c|}{----- } & \multicolumn{2}{|c|}{------ } \\
\hline male & & & & & 1.1632 & & \multicolumn{2}{|c|}{2.16} & \multicolumn{2}{|c|}{$0.01154 *$} \\
\hline Baseline CD4 & -0.0052 & 0.0016 & -3.2072 & $0.0013^{*}$ & -0.0048 & 0.0015 & & & & 00104* \\
\hline \multicolumn{11}{|l|}{ Adherence } \\
\hline poor(R) & ------- & ------ & ------- & ---------- & --------- & ------ & \multicolumn{2}{|c|}{----- } & \multicolumn{2}{|c|}{------ } \\
\hline fair & -1.6769 & 0.8610 & -1.9476 & 0.0515 & -1.5801 & 0.7092 & \multicolumn{2}{|c|}{-2.2281} & & $.0259 *$ \\
\hline good & -1.2532 & 0.6704 & -1.8693 & 0.0616 & - & 0.54 & & 574 & & 04154* \\
\hline HIV/TB & & & & & & & & & & \\
\hline HIV/TB(R) & ---------- & ------ & ------- & ---------- & ---------- & ---------- & & & ---- & \\
\hline HIV/TB(yes) & 2.101 & 0.676 & 3.100 & $0.0210 *$ & 2.52 & 0.512 & & & 0.00 & $25^{*}$ \\
\hline Associations & & & & & & & & & & \\
\hline Gamma_1 & -0.6693 & 0.336 & -0.1 .992 & $0.0367 *$ & -0.3666 & 0.1600 & & & & $00487 *$ \\
\hline Gamma_2 & -1.975 & 1.0065 & -1.9627 & $0.02798^{*}$ & - & 1.2347 & & & & $04142 *$ \\
\hline AIC & & 6602.83 & & & & 283 & 126 & & & \\
\hline Parameters & Longitud & $\begin{array}{l}\text { 1al process } \\
\text { on Tim }\end{array}$ & $\begin{array}{l}\text { sub mode } \\
\text { le-To Deatl }\end{array}$ & of $\sqrt{C D 4 \text { cell }}$ & $\begin{array}{l}\text { Longituc } \\
\qquad \log \end{array}$ & $\begin{array}{l}\text { dinal proce } \\
g(\text { weight }) \mathrm{v}\end{array}$ & & $\begin{array}{l}\text { del o } \\
\text { To I }\end{array}$ & $\begin{array}{l}\sqrt{C D} \\
\text { eath }\end{array}$ & $\overline{4 \text { cell } \&}$ \\
\hline Fixed effect & $\hat{\mathrm{B}}$ & $\operatorname{Se}(\hat{B})$ & z-value & $\operatorname{Pr}(>|z|)$ & $\hat{\mathrm{B}}$ & & & $\mathrm{z}-\mathrm{v}$ & lue & $\begin{array}{l}\operatorname{Pr}( \\
>|z|)\end{array}$ \\
\hline (Intercept)_1 & 10.356 & 2.0583 & 5.0314 & $<0.0001^{*}$ & 10.46 & & & & & $\begin{array}{c}<0.0001 \\
*\end{array}$ \\
\hline time_1 & 0.0259 & 0.3835 & 0.0676 & 0.9461 & 0.0309 & & & 0.1 & 247 & 0.900 \\
\hline Baseline CD4_1 & 0.0208 & 0.0022 & 9.48 & $<0.0001 *$ & 0.0207 & & & 10. & 877 & $\begin{array}{c}<0.0001 \\
*\end{array}$ \\
\hline age_1 & -0.0015 & 0.0251 & -0.0586 & 0.950 & -0.0040 & & & -0.1 & 453 & 0.88 \\
\hline $\begin{array}{l}\text { Baseline } \\
\text { weight_1 }\end{array}$ & 0.0313 & 0.0279 & 1.1228 & 0.2615 & 0.0331 & & & & & 0.2655 \\
\hline Functional status & & & & & & & & & & \\
\hline
\end{tabular}




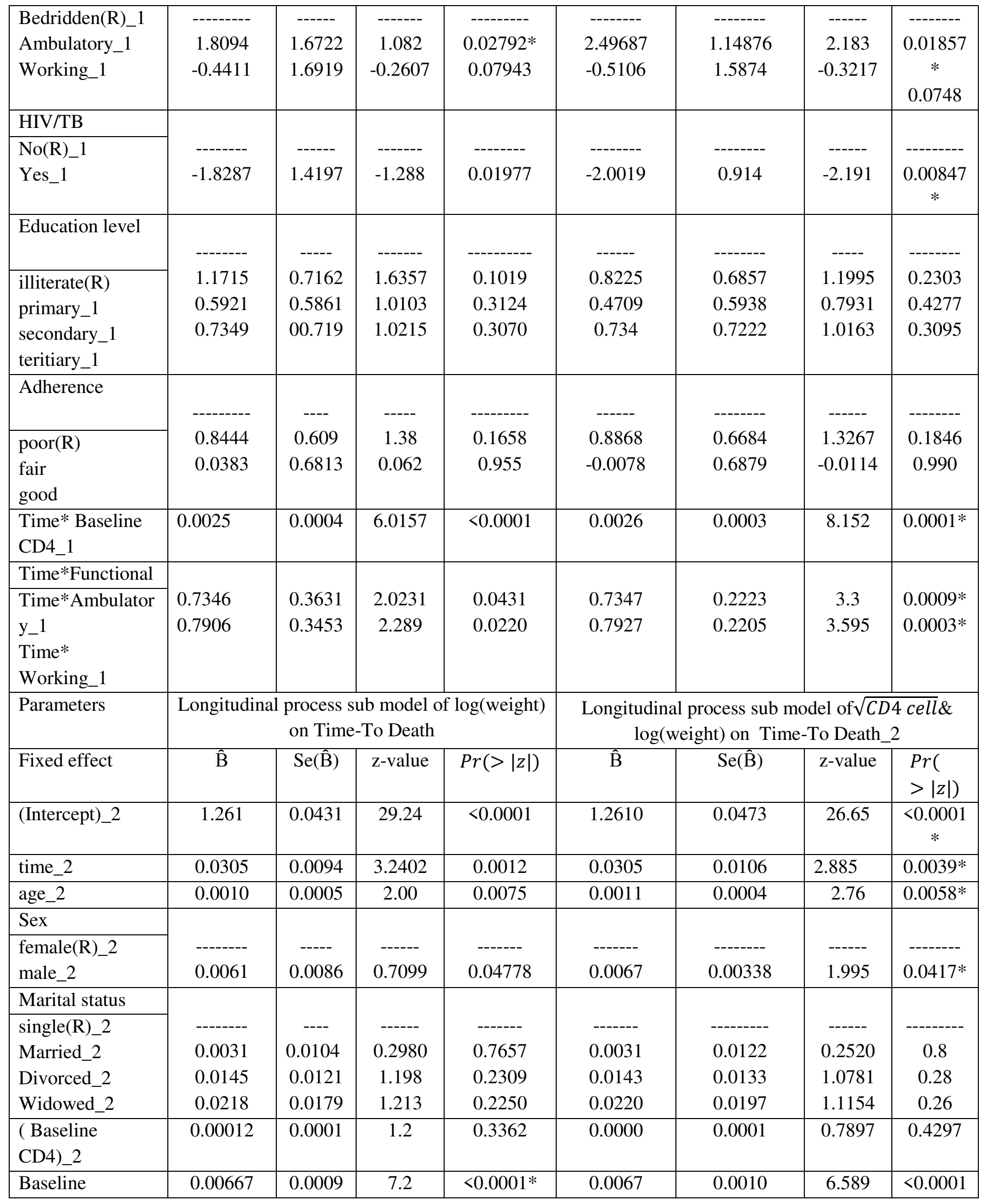




\begin{tabular}{|l|c|c|c|c|c|c|c|c|}
\hline weight._2 & & & & & & & $*$ \\
\cline { 1 - 4 } Functional status & & & & & & & & \\
\cline { 1 - 5 } Bedridden(R)_2 & ------- & ----- & ----- & ------ & ------ & ------ & ---- & ----- \\
Ambulatory_2 & 0.0372 & 0.024 & 1.55 & $0.0135 *$ & 0.0395 & 0.0150 & 2.625 & $0.0087 *$ \\
Working_2 & 0.0364 & 0.0575 & 0.633 & $0.0092^{*}$ & 0.0506 & 0.0176 & 2.866 & $0.0042^{*}$ \\
\hline
\end{tabular}

\section{Discussions}

In the present paper, the researchers tried to find the factors that affect log (bodyweight) \& $\sqrt{C D 4 \text { cell }}$ count progression sub-models on the short survival time-to-death of HIV/AIDS patients by fitting simultaneously. Baseline CD4, Fair, Good adherence, HIV/TB, and sex were significant factors of risk to short survival time-to-death of HIV/AIDS patients. Baseline CD4, Ambulatory functional status, HIV/TB, Time*Ambulatory functional status, Time*Working functional status, and Time*Baseline CD4 were significant factors of $\sqrt{C D 4 \text { cell }}$ count progression. On the other hand, visit time of follow-up, age, sex, Baseline weight, Ambulatory functional-status \& working functional-status were significant factors of log (bodyweight) progression. The associations of the count on survival time-to-death and log (Bodyweight) on survival time-to-death of HIV/AIDS patients was statistically significant when the two biomarkers of longitudinal repeated measurements with survival Time-to-Death were fitted simultaneously. That means, the association parameters were negative for both statistical joint models (, this indicated that inverse relationship between them) and this result is similar to an earlier study [25].

The risk of survival time to death on patients for those who had developed HIV/TB (yes) patients was more risk than those who had not developed HIV/TB (No) patients when controlling other independent variables. These results conformed to the studies conducted $[6,12]$. This shows that the main known risk factor for mortality in HIV/AIDS patients are TB development. There was also significant sex differential among patients on the risk of mortality of males had more affected as compared with females by controlling other predictor variables. This study contradicts the previous study [14]. The risk of death of HIV/AIDS patients whose Adherence Fair and Good had lower than those whose Adherence Poor by controlling other predictor variables. This shows that HIV/AIDS patients whose Adherence was Fair and Good have better survival time $\&$ understanding of the disease condition and comprehension of instructions given on drug usage than Adherence poor patients and this observation agrees with the study conducted earlier[26]. Moreover, those patients who had lower baseline CD4 were associated with a higher 
risk of death among the retrospective cohort. That means the patient's baseline CD4+ count significantly impacts his or her survival time. This study was agreed with a study $[6,12]$.

The progression change of $\sqrt{C D 4 \text { cell }}$ count on patients for those who had developed HIV/TB (yes) patients was less than those who had not developed HIV/TB patients when controlling other independent variables. This study agreed with the findings of [12]. On the functional status of patients on ART, The progression change of $\sqrt{C D 4 \text { cell }}$ count for Ambulatory Functional status patient's more as compared to Bedridden Functional status patients by controlling other independent variables. This shows that patients whose Bedridden Functional statuses have a higher probability of risk of death than patients whose Ambulatory Functional status. This result is in agreement with the earlier findings [26]. Baseline CD4 cell count was positively associated with progression change of $\sqrt{C D 4 \text { cell }}$ count during ART treatment. That means High baseline CD4 count was contributed to the increase of $\sqrt{C D 4 \text { cell }}$ count progression. This result was similar to an earlier study that reported positive associations between these characteristics [27].

The interaction effect of visit time follow-up by functional status had a statistically significant effect on the mean $\sqrt{\boldsymbol{C D 4} \text { cell }}$ count, this suggesting that as the number of visit time increased the average $\sqrt{\boldsymbol{C D 4} \text { cell }}$ count of HIV/AIDS patients who were ambulatory and working functio nal status was higher than the average $\sqrt{\text { CD4 cell }}$ count of patients who were bedridden functional status by 2 times (p-value $=0.0009)$ and 2.2 times (p-value $=0.0003$ ) respectively when other variables constant. The length of stay of follow-up on ART was an important predictor of improvement on the log of bodyweight progression of patients (Beta $=0.0305$; $\mathrm{p}$ value $=0.0039$ ). Such kind of result also found [13]. The progression change of log (bodyweight) has positively associated with the baseline body weight. This indicated higher body weight at baseline was found to be associated with higher progression on the log (bodyweight). The results of the present study confirmed the study reported previously [14]. Similarly, the longitudinal joint sub-model of log (bodyweight) ambulatory and working functional status were significant factors for contributing to the prediction of HIV/AIDS patients of bodyweight progression. That means that ambulatory \& actively working patients had better log body weight than bedridden patients as reported earlier [13]. It means, higher age predicted improvement in the log of body Weight progression which is similar to the earlier study [14]. 


\section{Conclusion}

By studying the relationship between the two biomarkers such as CD4cells and bodyweight progression on the survival time and time to death, the authors have concluded that they were negatively significant and that the Statistical Joint Model performed better. Thus, the authors concluded that the Statistical Join Model was better for simultaneous analyses of repeated biomarker measurements and survival time to death. Thus, the statistical joint model should be preferred over separate models for the two longitudinal and survival data analysis.

Finally, the association parameters were negative for both statistical joint models. Hence, this indicated that the higher $\log 10$ (Body-Weight) $\& \sqrt{\text { CD4 cell }}$ count progression is significantly associated with the lower risk of survival Time-To-death. This shows that as $\sqrt{\boldsymbol{C D 4} \text { cell }}$ count $\& \log 10$ (body weight) increased the mortality rate was decreased. We recommend that there should be special attention for HIV-positive adults, especially for those who had developed HIV/TB, male, bedridden functional status, poor adherence, and lower Baseline CD4 cell count progression. To address this problem, continuous timely medical care should be important to minimize the risk of death and we suggested that Health experts measure the repeated biomarkers. Because these were an important indicator for planning methods to minimize morbidity and mortality rates due to HIV/AIDS diseases. Moreover, we suggested that other researchers of this nature include other important covariates such as viral load results, opportunistic infections, economic status, religion, smoking status, alcohol drinking, and many other such risk factors playing a great role in this study.

\section{Limitations of the study}

We were unable to include important various sociodemographic and socioeconomic variables like, consumption of alcohol, viral load, smoking, income level, physical activity, and diet style that might have contributed to the survival times death of the HIV/AIDS patients. Globally, Tobacco, Alcohol, and Obesity are the major causes of death that have increased substantially since 1990 in some large populations, and thus, missing such variables never been missed in any death-related studies. Moreover, the present study was restricted to age group $>=15$, due to their different measures of CD4 cell count HIV/AIDS patients for children and adults.

\section{Abbreviations}

AIC

AIDS

ART
Akaike Information Criteria

Acquired Immune Deficiency Syndrome

Antiretroviral Therapy 


\begin{tabular}{ll} 
BIC & Bayesian Information Criteria \\
CD4 & Cluster Differentiation 4 \\
GFTAM & Global Fund for Tuberculosis, AIDS and Malaria \\
HIV & Human Immunodeficiency Virus \\
HAART & High Active Anti-Retrieval Virus \\
LMM & Linear Mixed Model \\
ML & Maximum Likelihood \\
PEPFAR & President Emergency Plan for AIDS RElief \\
REML & Restricted (or residual) maximum likelihood \\
JM & Joint Modeling \\
TB & Tuberculosis \\
UNAIDS & Joint United Nations Program on HIV/AIDS \\
WHO & World Health Organization Clinical Stage \\
Declarations & \\
\multicolumn{2}{l}{ Ethics approval and consent to participate }
\end{tabular}

Ethical clearance was obtained from the Ethical Review Committeeof University of Gondar College of Natural and Computational Science. The names of the subjects were not extracted to insure privacy of HIV/AIDS patients and confidentiality was maintained throughout data collection process and analysis. To collect the data, permission was obtained from administrative officers of Mekelle general hospital.

\section{Consent for publication}

Not Applicable.

\section{Availability of data and material}

Authors have Considered HIV/AIDS datasets from Mekelle General Hospital patient history card and now, attached as supplementary materials of the submission system.

\section{Competing interests}

The authors declare that they have no competing interests.

\section{Funding}

This study was financially supported by the Department of Statistics, University of Gondr, Ethiopia. It is a limited standard budget for postgraduate students; basically for data collection and duplication. 


\section{Authors' contributions}

GGG has made contributions on conceptualized the research problem, acquisition of data, designed the study, performed statistical analysis, interpretation of data and revised \& drafting the manuscript. ZGA and DMC have made a great role in re-vision of the research design, data analysis, manuscript write-up, editing the entire manuscript and ready for publication. Finally, all authors have read and approved the final manuscript before submission.

\section{Acknowledgements}

The authors would like to express their profound gratitude to the Management of Mekelle General Hospital for unlimited access to the pertinent medical registers from which they could extract the data used for current study. Moreover, the authors are highly thankful to Gondar University Postgraduate Program Directorate for subsidizing finance throughout the entire study.

\section{References}

1. WHO Global Health Observatory (GHO) Data, HIV/AIDS: Global Situation and Trend. 2017. http://www.who.int/gho/hiv/en/ Accessed 15 Oct 2017.

2. UNAIDS: Global AIDS Update: Enormous Gains, Persistent Challenges, 2016.

3. WHO, Media Centre, HIV/AIDS, Fact Sheet: Updated July 2017.

4. UNAIDS. UNAIDS/AIDS REPORT. Springer; 2018. p. 7-10.

5. Seyoum A, Temesgen Z. Joint longitudinal data analysis in detecting determinants of CD4 cell count change and adherence to highly active antiretroviral therapy at FelegeHiwot Teaching and Specialized Hospital, North-west Ethiopia (Amhara Region). AIDS research and therapy. 2017;14(1):14.

6. Tadege M. Time to death predictors of HIV/AIDS infected patients on antiretroviral therapy in Ethiopia. BMC research notes. 2018;11(1):761.

7. Gezae KE, Abebe HT, Gebretsadik LG. Incidence and predictors of LTFU among adults with TB/HIV co-infection in two governmental hospitals, Mekelle, Ethiopia, 2009-2016: survival model approach. BMC infectious diseases. 2019;19(1):107.

8. Kaufmann GR, et al. CD4 T-lymphocyte recovery in individuals with advanced HIV-1 infection receiving potent antiretroviral therapy for 4 years: the Swiss HIV Cohort Study. Arch Intern Med. 2003;163(18):2187-95.

9. Awoke Seyoum, Principal Ndlovu and ZewotirTemesgen. Joint longitudinal data analysis in detecting determinants of CD4 cell count change and adherence to highly active antiretroviral 
therapy at FelegeHiwot Teaching and Specialized Hospital, North- west Ethiopia (Amhara Region). AIDS Res Ther (2017) 14:14.

10. Florence E, et al. Factors associated with a reduced CD4 lymphocyte count response to HAART despite full viral suppression in the EuroSIDA study. HIV Med. 2003;4(3):255 62.

11. Collett D. Modelling survival data in medical research: Chapman and Hall/CRC; 2015.

12. Damtew B, Mengistie B, Alemayehu T. Survival and determinants of mortality in adult HIV/Aids patients initiating antiretroviral therapy in Somali Region, Eastern Ethiopia. Pan African Medical Journal. 2015;22(1).

13. Temesgen A, Kebede T. Joint Modeling of Longitudinal CD4 Count and WeightMeasurements of HIV/Tuberculosis Co-infected Patients at Jimma University Specialized Hospital. Annals of Data Science. 2016;3(3):321-38.

14. Reda AA, Biadgilign S, Deribew A, Gebre B, Deribe K. Predictors of change in CD4 lymphocyte count and weight among HIV infected patients on anti-retroviral treatment in Ethiopia: a retrospective longitudinal study. PLoS One. 2013;8(4):e58595.

15. AYALEW, J., MOGES, H. \& WORKU, A. 2014. Identifying factors related to the survival of AIDS patients under the follow-up of antiretroviral therapy (ART): The case of South Wollo. Int. J. Data Envelopment Anal. Oper. Res, 1, 21-27.

16. WEST, B. T., WELCH, K. B. \& GALECKI, A. T. 2014. Linear mixed models: a practical guide using statistical software, Chapman and Hall/CRC.

17. DIGGLE, P. J., SOUSA, I. \& CHETWYND, A. G. 2008. Joint modelling of repeated measurements and time- to- event outcomes: the fourth Armitage lecture. Statistics in Medicine, 27, 2981-2998.

18. VERBEKE, G. \& MOLENBERGHS, G. 2000. A model for Longitudinal Data. Linear mixed models for longitudinal data, 19-29.

19. WEISS, R. E. 2005. Modeling longitudinal data, Springer Science \& Business Media.

20. TEMESGEN, A., GURMESA, A. \& GETCHEW, Y. 2018. Joint Modeling of Longitudinal CD4 Count and Time-to-Death of HIV/TB Co-infected Patients: A Case of Jimma University Specialized Hospital. Annals of Data Science, 5, 659-678.

21. RIZOPOULOS, D. 2012. Joint models for longitudinal and time-to-event data: With applications in R, Chapman and Hall/CRC.

22. RIZOPOULOS, D. D. 2010. JM: An R package for the joint modelling of longitudinal and time-to-event data. Journal of Statistical Software (Online), 35, 1-33. 
23. LAIRD, N. M. \& WARE, J. H. 1982. Random-effects models for longitudinal data. Biometrics, 38, 963-974.

24. GROVER, G., SWAIN, P., DEO, V. \& VARSHNEY, M. 2015. A Joint Modeling Approach to Assess the Impact of CD4 Cell Count on the Risk of Loss to Follow up in HIV/AIDS Patients on Antiretroviral Therapy. International Journal of Statistics and Applications, 5, 99108.

25. HICKEY, G. L., PHILIPSON, P., JORGENSEN, A. \& KOLAMUNNAGE-DONA, R. 2016. Joint modelling of time-to-event and multivariate longitudinal outcomes: recent developments and issues. BMC medical research methodology, 16, 117.

26. AHUNIE, M. A. \& EBRAHIM, E. A. 2017. Mortality predictors of HIV-infected patients on antiretroviral therapy in Debre Tabor General Hospital and Woreta Health Center, South Gondar Zone, Northwest Ethiopia.

27. ADAMS, M. \& LUGUTERAH, A. 2013. Longitudinal analysis of change in CD4+ cell counts of HIV-1 patients on antiretroviral therapy (ART) in the Builsa district hospital. European Scientific Journal, ESJ, 9. 


\section{Supplementary Files}

This is a list of supplementary files associated with this preprint. Click to download.

- Supplementaryforall.docx 